\title{
The Impact of Taxes on Intra-week Stock Return Seasonality
}

\author{
Virgilijus Sakalauskas and Dalia Kriksciuniene \\ Department of Informatics, Vilnius University, \\ Muitines 8, 44280 Kaunas, Lithuania \\ \{virgilijus.sakalauskas, dalia.kriksciuniene\} avukhf.lt
}

\begin{abstract}
In this paper we explore the impact of trading taxes (commissions) on day-of-the-week effect in the Lithuanian Stock market. We applied the computational model for processing trading activities only on the particular days of the week. The suggested algorithm of trading shares not only reveals presence of the day-of-the-week anomaly, but allows comparing it to the influence of the trading taxes by estimating the final return of the selected shares. As the taxes of each transaction depend on the investment sum, therefore the suggested algorithm had to optimize the number of operations for ensuring the biggest gain. The research revealed significance of intra-week stock return seasonality for majority of shares (17 out of total 24). The advantages of the suggested method include its ability to better specify the shares for performing intra-week seasonality-based transactions, even though embracing of the trading commissions reduces visibility of the effect.
\end{abstract}

Keywords: stock return, day-of-the-week effect, seasonality, operation taxes, trading strategy.

\section{Introduction}

Together with the internationalization of economics and finance activities and increasing on-line possibilities for trading in various financial markets of the world, the investors acquire wider powers to manage the investment portfolio. The variety of trading conditions urges to look for the markets with bigger return of investment and lower risk. Most developed markets are highly integrated and similar in profitability, therefore more attentive look of the investors is now aimed to the emerging stock markets. The abilities to indicate and exploit various trading anomalies could be helpful for gaining higher returns.

One of such anomalies is the day-of-the-week effect, which presumes that significantly different returns are regularly occurring for some particular trading day of the week. Mondays and Fridays are indicated as the trading days, mostly affected by this anomaly. Indicating the days of the week with the return, significantly different from the other days, could allow us to design the algorithm of profitable strategy.

Therefore, documenting and testing of intra-week seasonality anomalies across various markets is the interesting and ultimate task both for the researchers and traders. The research literature on the day-of-the-week stock return anomaly focuses 
mainly on the United States and other advanced economies [1-6] with the inadequately low attention to the emerging markets, including those of the Eastern Europe. Recently the emerging stock markets became more interesting for the researchers, as the day-of-the-week effect in the developed stock markets from 1990s was confirmed as fading [7-11].

Basher, S.A. and Sadorsky, P. in [11] have studied the day of week effect in 21 emerging stock market by using both unconditional and conditional risk analysis and applying different analysis models. They concluded that "while the day-of-the-week effect is not present in the majority of emerging stock markets studied, some emerging stock markets do exhibit strong day-of-the-week effect"“.

The empirical investigation of the day-of-the-week stock return anomaly was made by Ajayi R.A. et al by using major market stock indices in eleven Eastern European emerging markets [12]. The research outcomes indicate negative Monday returns in six of the Eastern European markets and positive Monday returns in the remaining five. Two of the six negative Monday returns and one of the five positive Monday returns were statistically significant.

The day-of-the-week effect in the emerging Lithuanian Stock market was investigated by authors in [13], [14], by using traditional statistical analysis methods. The research lead to the conclusion that day-of-the-week effect had no significant influence to the Vilnius Stock OMX Index return, and there were only few shares (not more than 4 from 24, as confirmed by applying different analysis methods), where affected by this anomaly.

More investigation results of the day-of-the-week effect were obtained by using artificial neural networks [15]. Two standard types of neural networks were applied: MLP (Multilayer Perceptrons) and RBF (Radial Basis Function Networks). The research outcomes revealed better sensitivity of the neural networks. Monday effect was present for 11 shares, and Friday effect was present for 9 out of total list of the 24 analysed stocks.

In this article we analyse the impact of taxes on intra-week stock return seasonality. We suggested the computational model for calculating the accumulated return by making trading activities on particular days of the week. The proposed trading strategy allows to reveal presence of the day-of-the-week anomaly and to estimate the influence of trading taxes on final return of the selected shares. The experimental research of the computational method employed the financial trading data of 24 shares of the Vilnius Stock Exchange (from 2003-01-01 to 2008-01-11).

In the following sections we present the computational model, designed for implementing stock trading algorithm, define the organization of research data set and present the results of experimental research. The research conclusions address the impact the day-of-the-week effect, influence of the sales commissions, and the problem of number of trading operations for the accumulated return of investment.

\section{Computational Model for Stock Trading Strategy}

In this part we present the computational model for evaluating the possible accumulated return of stock trading, exploiting the day of the week effect. The model is designed for taking into account the influence of commission taxes, trading volume and 


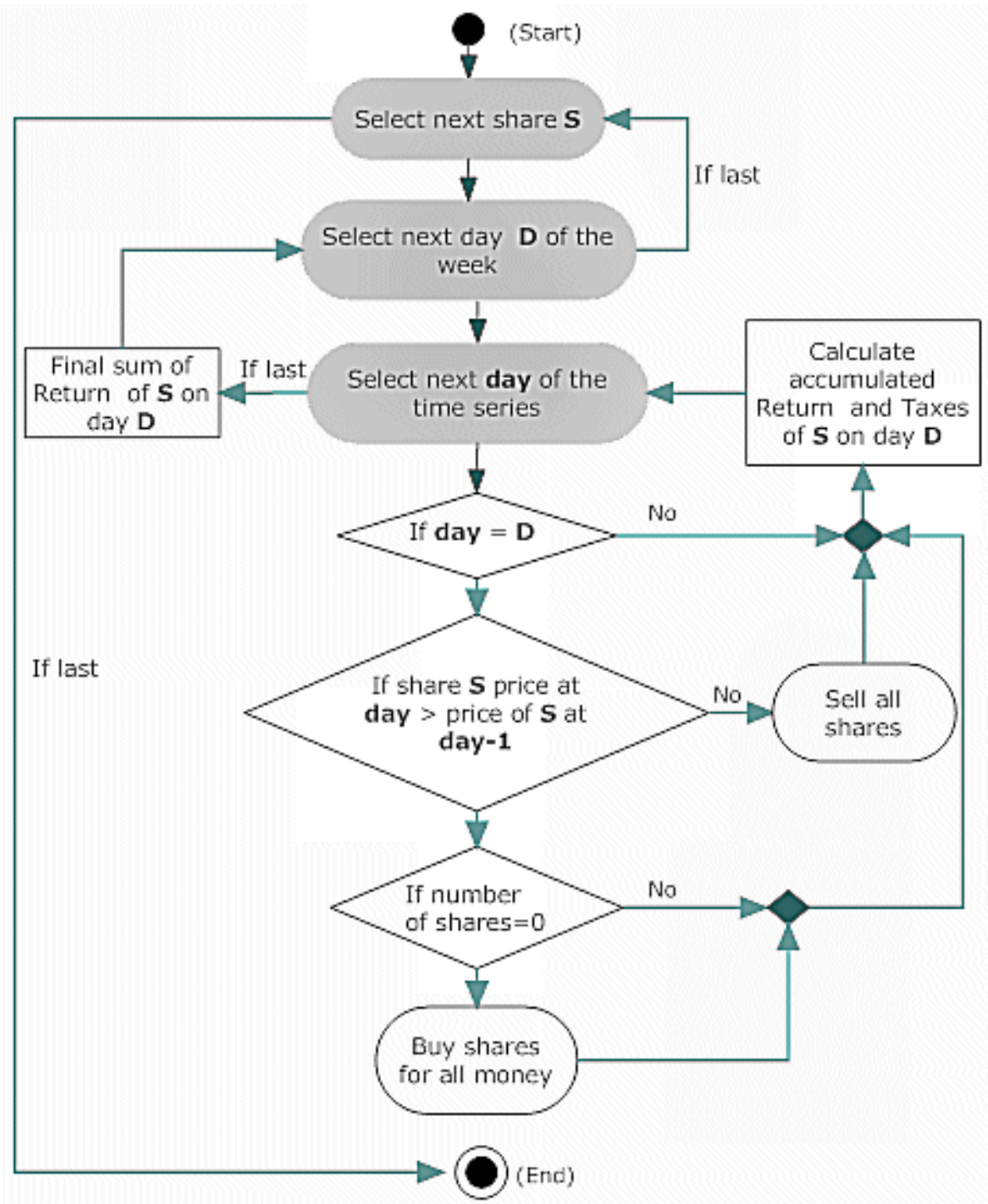

Fig. 1. Trading strategy algorithm

number of transactions, executed for application of the designed trading algorithm. Such trading strategy gives us possibility to define the days of the week, which could be confirmed as significantly different, than the other days of the week, according to the estimated accumulated return (either higher or lower).

For implementing this strategy, the trading operations were executed only on particular days of the week and the accumulated return was estimated with and without trading commissions. Most research works neglect the impact of taxes, charged for the trading operations, or do not check the influence of this condition to intra-week 
seasonality. As each operation bears the taxes of quite big value comparing to the stock price fluctuations, the trading frequency is very important parameter as well, which can lower the return considerably. In order to imitate real trading situation, the $0.3 \%$ commissions rate was applied for the experimental data, described in the section 3. This rate is quite big and requires applying conservative trading strategy to the sufficient extent so that the total return was not totally dissolved by the trading taxes.

The stock trading strategy, implemented in the suggested algorithm is aimed to reveal presence the day-of-the-week effect, and to check if it was financial worth to take into account the day of the week of the transaction, and the frequency of trading operations. At the same time, our task was not formulated as the goal to create optimal investment strategy with the maximal return on investment, but to indicate exceptional trading outcomes by making transactions on particular days of the week.

According to the algorithm, we calculate the accumulated sum of return for selected stocks for each day of the week. We make the buying transaction only when the market is rising and the selling transaction on the day of the falling prices. In each case the trading transaction is made for all available sum of money. The accumulated return in each case is calculated in two ways: including and not including taxes. Therefore the positive return of any trading day cannot be illustrated by trade operations made on the opening and close moments of that day, as the trading taxes could exceed the generated profit. For experimental research of the trading algorithm we selected the initial investment sum 100 LTL. In this case the final earned sum of return denoted the percent rate of return. The trading algorithm is presented in Fig. 1.

By using this strategy we have possibility to research influence of number of trading operations for the final accumulated return, as this has the total impact of taxes as well. The day-of-the-week based strategy gives us the possibility to identify exclusive values of return.

\section{Experimental Data and Research Results}

The performance of the algorithm was analysed by processing of the financial data of the Vilnius Stock Exchange. Vilnius Stock Exchange belongs to the category of small emerging securities markets characterized by comparatively low volume, low liquidity and high volatility. It can be described by the following characteristics: market value is 7 EUR billions, near 2 million EUR of share trading value per business day, approximately 600 trading transactions per business day, and 45 shares in the equity list [16].

The experimental data set was created of the financial data of 24 most actively traded shares listed at the Vilnius Stock Exchange during the time interval from 200301-01 to 2008-01-11 on daily basis. The trading data was assigned to the variables, named according to their acronyms in the Vilnius Stock Exchange [16], which are further used for presenting research results in this article.

The selected set of stock data represents all variety of the list, according to the capitalization, number of shares, daily turnover, profitability and risk. The dynamics of the stock prices during the period of analysis is well reflected by the profile of OMX Vilnius Stock Index (Fig.2), which is a capitalization weighted chain linked total-return index. 


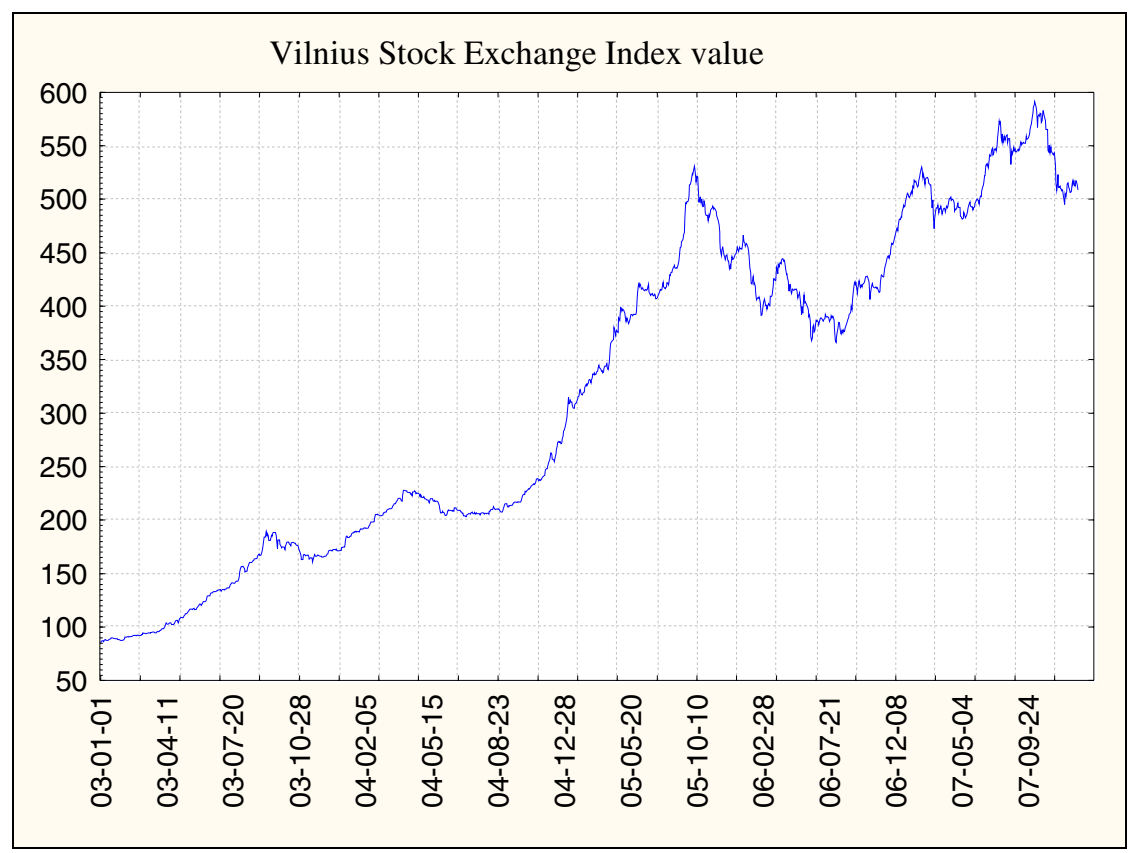

Fig. 2. OMX Index values of the Vilnius Stock Exchange

In Fig. 2 the period of 2003.01 to 2005.10 can be characterized by the average increase of stock prices which went up to about 5 times, with moderate fluctuations. Starting from 2005.10 till 2006.08 was the period of quite harsh decrease, than followed by significant rising of price level during the whole following year. At the same time the price volatility increased as well. The stock market price crisis of the end of 2007 had influence to the trading situation of Vilnius Stock Exchange in Lithuania. The recent period of more stable stock prices still shows quite big price fluctuations. Therefore the described features of the historical stock trading data can substantiate that the designed database covers sufficient amount of financial data, wide variety of real trading situations in the financial market, and can ensure validity of the experimental research.

The data cleansing procedures of the stock information time series included removal of non-trading records during the holidays, weekends and the records of the trading days with zero number of deals. After processing the data set the average number of daily trading records for each share was approximately 1100 , thus ensuring necessary amount of experimental data for getting significant findings. For mining the data and calculations we used STATISTICA and MS EXCEL software.

By using the share trading strategy (Fig. 1), outlined in the section 2, we calculated the final return of selected shares for all days of the week. In Table 1 the final accumulated return of share trading according to the designed computational model and algorithm included the trading commissions of $0.3 \%$ of the invested sum. 
In the Table 1, the final return value of the stocks, which are significantly different $(p<0.05)$ from the values of other days of the week are marked in bold font. Therefore these values indicate the days of the week, affected by the day-of-the-week anomaly.

Table 1. Final trading return after investing $100 \mathrm{Lt}$, by days of the week (including taxes)

\begin{tabular}{|c|c|c|c|c|c|c|}
\hline & $\begin{array}{c}1 \\
\text { Monday } \\
\end{array}$ & $\begin{array}{c}2 \\
\text { Tuesday }\end{array}$ & $\begin{array}{c}3 \\
\text { Wednesday }\end{array}$ & $\begin{array}{c}4 \\
\text { Thursday }\end{array}$ & $\begin{array}{c}5 \\
\text { Friday }\end{array}$ & $\begin{array}{c}6 \\
\text { MEAN }\end{array}$ \\
\hline $\begin{array}{ll}\text { LEL } \\
\end{array}$ & 219 & 285 & 285 & 249 & 205 & 248,6 \\
\hline KBL & 71 & 61 & 51 & 72 & 123 & 75,6 \\
\hline LNS & 36 & 47 & 57 & 129 & 138 & 81,4 \\
\hline LEN & 132 & 83 & 163 & 437 & 121 & 187,2 \\
\hline VBL & 190 & 94 & 59 & 225 & 127 & 139,0 \\
\hline LJL & 90 & 88 & 126 & 91 & 35 & 86,0 \\
\hline LLKK & 215 & 137 & 124 & 117 & 146 & 147,8 \\
\hline KJJK & 141 & 283 & 159 & 230 & 420 & 246,6 \\
\hline ZMP & 156 & 161 & 131 & 101 & 112 & 132,2 \\
\hline LD.J & 70 & 119 & 118 & 76 & 103 & 97,2 \\
\hline RST & 159 & 102 & 120 & 148 & 181 & 142,0 \\
\hline UTR & 80 & 70 & 106 & 68 & 38 & 72,4 \\
\hline NDL & 240 & 152 & 181 & 196 & 110 & 175,8 \\
\hline SAN & 471 & 93 & 304 & 416 & 128 & 282,4 \\
\hline KNF & 107 & 102 & 60 & 77 & 76 & 84,4 \\
\hline PTR & 893 & 322 & 341 & 406 & 221 & 436,6 \\
\hline PZV & 219 & 88 & 105 & 169 & 152 & 146,6 \\
\hline $\mathrm{APG}$ & 83 & 131 & 112 & 387 & 80 & 158,6 \\
\hline MNF & 146 & 336 & 250 & 145 & 308 & 237,0 \\
\hline SNG & 69 & 66 & 63 & 36 & 72 & 61,2 \\
\hline UKB & 373 & 104 & 228 & 206 & 271 & 236,4 \\
\hline RSU & 112 & 99 & 83 & 709 & 241 & 248,8 \\
\hline LFO & 180 & 204 & 249 & 192 & 212 & 207,4 \\
\hline TEO & 80 & 65 & 67 & 88 & 144 & 88,8 \\
\hline MEAN & 188,8 & 137,2 & 147,6 & 207,1 & 156,8 & 167,5 \\
\hline
\end{tabular}

The average profitability of all days of the week is close to the total average value of 167.5 (as presented in the last row of Table 1). This result supports the conclusion of the [14] stating that the mean return value of the Vilnius Stock OMX Index is not impacted by the day-of-the-week effect.

Only 7 stocks of the total analysed 24, namely MNF, KNF, SAN, ZMP, LDJ, LNS, LEL, have no significantly different days by means of profitability. Therefore the majority of stocks of the Vilnius Stock Exchange are impacted by the day-of-the-week 
effect. The most exclusive trading day is Friday, as the day-of-the-week anomaly is confirmed for 6 shares, and the Monday effect is noticed for five shares. The other days were only occasionally marked as significantly different, thus Monday and Friday effects had important trading impact in the observed market, similarly to the developed markets.

On the other hand, our experiment did not confirm traditional understanding that the lowest return is on Monday, and the highest - on Fridays. The results showed that in most cases the presence of the day-of-the-week effect meant the highest values of return, and only in 5 cases the significant results denoted the lowest values of accumulated return.

For performing analysis of influence of the commissions to the final return and to the significance of the day-of-the-week anomaly we compared the results including taxes (Table 1) and without them (Table 2). In both cases the same trading strategy (Fig 1) was applied for calculations. By comparing results of Table 2 and Table 1 we have to admit obvious difference in the accumulated values of final return.

From Table 1 and 2 we can notice good match of most cases the exceptional values, which indicate presence of the intra-week stock return seasonality. In Table 2 several additional stocks are marked as affected by the day-of-the-week anomaly (ZMP, LDJ, KNF). The effect itself is more visible, as the exceptional values differ clearer from the others. Thus we can conclude that by not taking into account the trading commissions we can make false identification of shares, denoting them as affected by the day-of-the-week anomaly.

The importance of the number of trading operations to identify significant return values in Tables 1 and 2 can be suggested by the research outcome, as omitting taxes $(0.3 \%)$ increased the expected accumulated return by $38.5 \%$. The biggest difference was estimated for LJL shares - even $118.6 \%$. This result was impacted by the maximal value of 178 sell/buy operations, performed by applying the trading algorithm. The average number of trading operations per share was 115 , which means that the investment portfolio approximately is changed every 10 days. By applying the algorithm we make on average 100 buy/sell operations with one share during the five trading years. This number of operations is comparatively low and allows expecting profitable outcome of trading stocks.

The standard deviation of the number of operations for the particular days of the week is quite low - 3.4. This means that the number of trading operations does not affect the occurrence of the day-of-the-week effect. It also points to stability of the suggested computational model, as day-of-the-week effect is the outcome of difference in return for particular days of the week, but not of the parameters of trading algorithm.

One of the research aspects was to analyse, if the shares grouped according to different trading volumes, differed in their profitability, and if the day-of-the-week effect was related to the trading volume. In Table 1 the list of shares is sorted according to their average daily trading volumes in ascending order. The difference in trading volumes of the stocks was quite evident, as the lowest daily turnover (stocks LEL and KBL) was about 15 thousand LTL ( 1 EUR=3.45 LTL), and the highest turnover (TEO stock) reached 700 thousand LTL. 
From the Table 1 and 2 any dependence of the day-of-the week effect and the trading volume could not be confirmed. This conclusion conforms to the research results, obtained by using traditional statistical methods in [15].

Table 2. Final trading return after investing $100 \mathrm{Lt}$, by days of the week (without taxes)

\begin{tabular}{|c|c|c|c|c|c|c|}
\hline & $\begin{array}{c}1 \\
\text { Monday }\end{array}$ & $\begin{array}{c}2 \\
\text { Tuesday }\end{array}$ & $\begin{array}{c}3 \\
\text { Wednesday }\end{array}$ & $\begin{array}{c}4 \\
\text { Thursday }\end{array}$ & $\begin{array}{c}5 \\
\text { Friday }\end{array}$ & $\begin{array}{c}6 \\
\text { MEAN }\end{array}$ \\
\hline LEL & 315 & 412 & 408 & 360 & 298 & 358,6 \\
\hline KBL & 90 & 77 & 62 & 87 & 159 & 95,0 \\
\hline LNS & 54 & 91 & 90 & 210 & 209 & 130,8 \\
\hline LEN & 195 & 112 & 253 & 644 & 190 & 278,8 \\
\hline VBL & 266 & 147 & 100 & 334 & 186 & 206,6 \\
\hline LJL & 162 & 157 & 217 & 163 & 241 & 188,0 \\
\hline LLKK & 289 & 185 & 178 & 168 & 207 & 205,4 \\
\hline KJJK & 157 & 343 & 204 & 242 & 490 & 287,2 \\
\hline ZMP & 197 & 227 & 193 & 144 & 168 & 185,8 \\
\hline LD.J & 99 & 176 & 177 & 118 & 156 & 145,2 \\
\hline RST & 249 & 160 & 198 & 234 & 281 & 224,4 \\
\hline UTR & 97 & 88 & 131 & 84 & 55 & 91,0 \\
\hline NDL & 249 & 153 & 182 & 202 & 125 & 182,2 \\
\hline SAN & 647 & 85 & 436 & 479 & 99 & 349,2 \\
\hline KNF & 153 & 148 & 89 & 120 & 116 & 125,2 \\
\hline PTR & 1151 & 415 & 445 & 498 & 287 & 559,2 \\
\hline PZV & 330 & 137 & 157 & 246 & 226 & 219,2 \\
\hline APG & 117 & 197 & 130 & 560 & 143 & 229,4 \\
\hline MNF & 226 & 503 & 374 & 213 & 466 & 356,4 \\
\hline SNG & 100 & 84 & 80 & 63 & 89 & 83,2 \\
\hline UKB & 517 & 143 & 329 & 260 & 344 & 318,6 \\
\hline RSU & 145 & 150 & 39 & 1097 & 290 & 344,2 \\
\hline LFO & 227 & 251 & 329 & 241 & 268 & 263,2 \\
\hline TEO & 125 & 110 & 105 & 141 & 226 & 141,4 \\
\hline MEAN & 256,5 & 189,6 & 204,4 & 287,8 & 221,6 & 232,0 \\
\hline
\end{tabular}

In the articles [13], [14] the day-of-the-week anomaly was explored by applying traditional statistical research methods for the same share trading data of the Vilnius Stock Exchange. By applying t-test, one-way ANOVA, Levene and Brown-Forsythe test of homogeneity of variances, the statistically significant difference among Monday/Friday and the other days of the week was observed only for some shares with medium trading volume. 


\section{Conclusions}

In major scientific research works the day-of-the-week effect is revealed by applying traditional statistical research methods, and the classification power of neural network or discriminant analysis.

In this work we explore impact of this effect in the Vilnius Stock Exchange by using the computational method for realization of the trading strategy, which allows highlighting the dependency accumulated return from the week day, selected for making trading transactions (buy/sell). The suggested trading strategy allowed to reveal presence of the day-of-the-week anomaly and to evaluate the influence of trading commissions to the accumulated return of selected share.

The experimental research was performed by using financial trading data set of 24 shares of Vilnius Stock Exchange (from 2003-01-01 to 2008-01-11). The suggested algorithm was applied for calculating return, accumulated by making investment operations only on the fixed trading day of the week in the Vilnius Stock Exchange. The effect was explored with and without commissions (equal to $0.3 \%$ from every buy/sell operation). Therefore the designed algorithm had to minimize the number of operations as well.

In case of calculation without transactions taxes, the application of the suggested method revealed significant impact of this effect for 20 out of 24 shares of the Vilnius Stock Exchange. The inclusion of the buy/sell commissions weakened the visibility of the day-of-the-week effect, and its significant presence could be confirmed only for 17 shares. Thus the research confirmed the assumption that the trading taxes must be included while exploring intra-week stock return seasonality. Otherwise the significant presence of the effect could be indicated for the shares with no impact of the effect to the final accumulated return.

The other conclusion of the research is related to the high importance of the number of buy/sell transactions for more reliable identification of the presence of the dayof-the-week effect. While applying trading algorithm to very intensive trading strategy, most part of the return is lost due to the commissions applied to the increasing sales volume. Our research showed that in the designed trading strategy the buy/sell activities were quite even distributed for all week days, and could not imply significant occurrence of exclusive stock returns.

The research of financial series of the Vilnius Stock Exchange did not confirm the common understanding that the return was marked to be lowest on Monday, and the biggest - on Fridays. Though the strongest effect was really indicated for Fridays and Mondays, but on Mondays the return value was not significantly lower. In contrast, the biggest value of return was recognized for 5 shares out of 6 (without taxes).

In research findings was also noticed the absence of significant impact of the trading volume to the occurrence of the day-of-the-week effect.

Comparing to the research [13], [14] elaborated by using traditional statistical methods, we concluded that the direct method of exploring presence of the day-ofthe-week effect, as applied in this work, was considerably more efficient.

The forthcoming directions of the research should deal with exploring stability of the obtained results by analysing the financial data set, updated by new stock trading data, and by implementing modifications to the stock trading algorithm. 


\section{References}

1. Connolly, R.A.: An examination of the robustness of the weekend effect. Journal of Financial and Quantitative Analysis 24, 133-169 (1989)

2. Cross, F.: The behaviour of stock prices on Fridays and Mondays. Financ. Anal. J. 29, 67-69 (1973)

3. Ho, Y.K., Cheung, Y.L.: Seasonal pattern in volatility in Asian stock markets. Appl. Finance Econom. 4, 61-67 (1994)

4. Jaffe, J.F., Westerfield, R., Ma, C.: A twist on the Monday effect in stock prices: evidence from the U.S. and foreign stock markets. Journal of Banking and finance 13, 641-650 (1989)

5. Steeley, J.M.: A note on information seasonality and the disappearance of the weekend effect in the UK stock market. Journal of Banking and Finance 25, 1941-1956 (2001)

6. Tong, W.: International evidence on weekend Anomalies. Journal of financial research 23(4), 495-522 (2000)

7. Brooks, C., Persand, G.: Seasonality in Southeast Asian stock markets: some new evidence on the day-of-the-week effects. Applied Economics Letters 8, 155-158 (2001)

8. Kamath, R., Chusanachoti, J.: An investigation of the day-of-the-week effect in Korea: has the anomalous effect vanished in the 1990s? International Journal of Business 7, 47-62 (2002)

9. Kohers, G., Kohers, N., Pandey, V., Kohers, T.: The disappearing day-of-the-week effect in the world's largest equity markets. Applied Economics Letters 11, 167-171 (2004)

10. Mills, T.C., Coutts, J.A.: Calendar Effects in the London Stock Exchange FTSE Indices. The European Journal of Finance 1, 79-93 (1995)

11. Basher, S.A., Sadorsky, P.: Day-of-the-week effects in emerging stock markets. Applied Economics Letters 13, 621-628 (2006)

12. Ajayi, R.A., Mehdian, S., Perry, M.J.: The Day-of-the-Week Effect in Stock Returns: Further Evidence from Eastern European Emerging Markets. Emerging Markets Finance and Trade, M.E. Sharpe, Inc. 40(4), 53-62 (2004)

13. Sakalauskas, V., Kriksciuniene, D.: Analysis of the Day-of-the-Week Anomaly for the Case of Emerging Stock Market. In: Neves, J., Santos, M.F., Machado, J.M. (eds.) EPIA 2007. LNCS (LNAI), vol. 4874, pp. 371-383. Springer, Heidelberg (2007)

14. Sakalauskas, V., Kriksciuniene, D.: Day of the week effect in small securities markets. In: Proceedings volume AIDSS of 9th International Conference on Enterprise Information Systems, Funchal, Portugal, 12-16, June 2007, pp. 432-436 (2007)

15. Sakalauskas, V., Kriksciuniene, D.: The impact of daily trade volume on the day-of-theweek effect in emerging stock markets. Information technology and control 36(1A), 152-158 (2007)

16. The Nordic Exchange, http: / /www.baltic. omxgroup.com/ 